\title{
A Fixed-Bed Column Study for Removal of Organic Dyes from Aqueous Solution by Pre-Treated Durian Peel Waste
}

\author{
Nguyen Thi Thuong ${ }^{1}$, Nguyen Thi Tuyet Nhi' ${ }^{2}$ Vo Thi Cam Nhung ${ }^{2}$, Hoang Ngoc Bich ${ }^{1}$, Bui Thi \\ Phuong Quynh ${ }^{3}$, Long Giang Bach ${ }^{1, *}$, and Trinh Duy Nguyen ${ }^{1}$ \\ ${ }^{1}$ NTT Hi-Technology Institute, Nguyen Tat Thanh University, Ho Chi Minh City 755000, Vietnam \\ ${ }^{2}$ Faculty of Food, Chemical \& Environmental Sciences, Nguyen Tat Thanh University, Ho Chi Minh City 755000, Vietnam \\ ${ }^{3}$ Faculty of Chemical Technology, Ho Chi Minh City University of Food Industry, Ho Chi Minh City 705800, Vietnam
}

\author{
*Corresponding author: \\ tel: $+84-969-294297$ \\ email: blgiang@ntt.edu.vn \\ Received: August 3, 2018 \\ Accepted: October 19, 2018
}

DOI: $10.22146 /$ ijc.39712

\begin{abstract}
A number of harmful effects on the ecosystem, the life of humankind, and living species caused by dye-contaminated wastewater have urged the development for an efficient and cost-efficient treatment method for colored effluents. The cellulose-based adsorbents have been considered as a facile and efficient approach to remove hazardous pollutants because of the abundance of inexpensive agricultural wastes in Viet Nam. This study aims to investigate the elimination of methylene blue $(M B)$ and crystal violet (VL) from wastewater using a fixed-bed column of pre-treated durian peel. Examined variables in the process are bed depths $(2-6 \mathrm{~cm})$, flow rate $(5-20 \mathrm{~mL} / \mathrm{min})$, and influent dye concentrations (200-600 mg/L). The highest adsorption amount of pre-treated DP was $235.80 \mathrm{mg} / \mathrm{g}$ and $527.64 \mathrm{mg} / \mathrm{g}$, respectively, on a $600 \mathrm{mg} / \mathrm{L}$ of methylene blue and crystal violet achieved within a bed height of $4 \mathrm{~cm}$ and a flow rate of $10 \mathrm{~mL} / \mathrm{min}$. Accordingly, the breakthrough curves were constructed and modeled using the relevant theoretical models under the effects of different experimental conditions. Pre-treated durian peel was found to exhibit high adsorption capacity for cationic dye in an initial concentration of 200-600 mg/L with complete removal being obtained.
\end{abstract}

Keywords: adsorption; durian peel; fixed-bed column; methylene blue; crystal violet

\section{- INTRODUCTION}

In the past few decades, the treatment of dyepolluted water has long been one of the most severe environmental problems faced by Vietnam and other developing countries because of the rapid growth of the textile industry. The coloring process discharges massive quantities of dye effluents into natural water bodies without adequate treatment. The presence of nonbiodegradable and highly toxic dyes in water resources can cause a serious problem of living species and human health. There has been a variety of physical, chemical and biological technologies available to control and minimize polluted water including precipitation, coagulation, filtration electrolysis, photodegradation, chemical oxidation, activated sludge and degradative enzymes, adsorption [13]. However, most of the mentioned methods had drawbacks due to high operational and maintenance expense and complexities in treatment procedure [4]. In contrast, the adsorption process is most favored on the ground of its high efficiency, cost-effectiveness, easy operation, and simple design, and feasibility for largescale applications [4-6]. Recently, adsorption process using a large variety of materials has attracted considerable interest for many advantages including high efficiency and selectivity, energy savings and low cost [7]. A wide range of natural agricultural by-product based adsorbents such as rice husks, sawdust, beer yeast, green algae, and fruit peels have been investigated too for the ability to decontaminate wastewater. Using these byproducts as adsorbents will bring two-fold advantage which is (1) decrease of the volume of agricultural waste and (2) water waste treatment at a reasonable cost. 
Durian, a tropical fruit, is a widespread agricultural commodity in Vietnam and many other Southeast Asia [8]. However, the edible parts only account for 40 percent of the weight of the fruit whereas the seeds and peels are arbitrarily discarded or incinerated after the consumption and thus resulting in severe environmental pollutions. To tackle such problem, some authors have utilized the microporous structure and large surface area of the durian peel to fabricate activated carbon used in the removal of solvents [9] and organic dyes [10-12]. Recently, low-cost biosorbents based on grounded and sieved raw durian peel also showed high efficacy when removing heavy metals [13]. However, unexpected components such as pectin, lignin, and waxes in the structure of durian peel affected to its adsorption efficiency for organic dyes, heavy metals and hence some studies investigated pre-treatment of durian shells with acids [14] to remove unexpected sources. The obtained results revealed the adsorption capacity of $63.29 \mathrm{mg} / \mathrm{g}$ for Acid green 25 from batch adsorption study. Accordingly, activated carbon products prepared from durian peel, durian seed, and durian shell were also investigated lying on high uptake capacity for removing organic and inorganic pollutants. For instance, the adsorption amount of durian shell based activated carbon for Methylene Blue was $289.26 \mathrm{mg} / \mathrm{g}$ reported by Chandra [11] and $410.85 \mathrm{mg} / \mathrm{g}$ recorded from Foo's study [15]. The activated carbon fabricated from durian peel treated with $\mathrm{HCl}$ under nitrogen atmospheric and vacuum pyrolysis condition showed the removal of $303.00 \mathrm{mg} / \mathrm{g}$ and $312.50 \mathrm{mg} / \mathrm{g}$, respectively, for Basic green 4 documented from Nuithitikul's report [16]. Ahmad et al. reported the adsorption amount up to $384.62 \mathrm{mg} / \mathrm{g}$ for Methyl red of activated carbon from durian seed [12]. Despite successful attempts on the removal of cation and anion dyes by adsorbents from durian peel, most of the earlier investigation was restricted to batch adsorption experiments in laboratory scale and only suitable when it comes to evaluating the adsorption capacities of the potential adsorbents under different physical-chemical process conditions. For transition into practical and large-scale operations, designing and optimization of the practical packed-bed column are required. In column mode, an appropriate quantitative model can be employed to analyze, predict and optimize the adsorption data upon changing operational conditions to identify process mechanisms. Therefore, in the present work, direct use of pre-treated durian peels as an efficient adsorbent for the organic dyes including Methylene blue and Crystal violet was investigated via fixed-bed column adsorption. Three considered factors of the adsorption process in this study are initial concentration, bed height, and flow rate. Accordingly, the breakthrough curves were constructed and modeled using the relevant theoretical models.

\section{- EXPERIMENTAL SECTION}

\section{Materials}

Sodium hydroxide, hydrochloric acid, and npropanol were purchased from Xilong Chemical Co, Ltd. The synthetic dyes, methylene blue (MB), congo red (CR) and crystal violet (VL) were provided from HiMedia Laboratories Pvt. Ltd., and the chemical structure of organic dyes were shown in Fig. 1. Durian peels (DP), collected as solid waste from local markets in Ho Chi Minh City, Vietnam, were washed with distilled water to remove adhering substances and dust and cut into small pieces $\left(2 \times 2 \mathrm{~cm}^{2}\right)$. The peels were then dried at $80{ }^{\circ} \mathrm{C}$ for $48 \mathrm{~h}$ and ground to fine particles. These grounded grain flours were sieved to get uniform particle

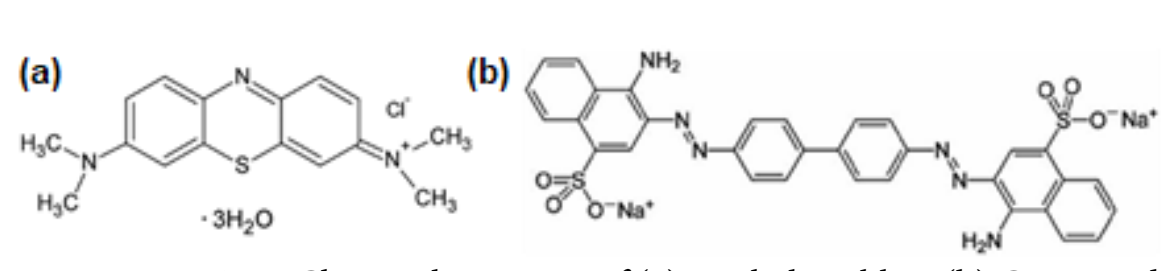

(c)

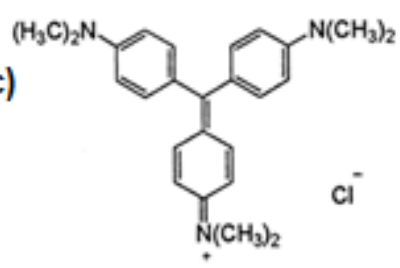

Fig 1. Chemical structure of (a) Methylene blue, (b) Congo red, (c) Crystal violet 
size below $250 \mu \mathrm{m}$ and then treated by $\mathrm{NaOH} 0.01 \mathrm{M}$ and isopropanol solution [17-18]. Lastly, the pre-treated DP were washed thoroughly with distilled water until $\mathrm{pH}$ 6-7 and dried in the oven at $80^{\circ} \mathrm{C}$ for $12 \mathrm{~h}$.

\section{Instrumentation}

The morphological examination of material was observed by scanning electron microscope (SEM) on the Hitachi S4800 instrument. To determine functional groups on the surface of adsorbents, Fourier transforminfrared (FTIR) spectra were measured in the range of $4000-400 \mathrm{~cm}^{-1}$ using a Bruker ALPHA spectrophotometer. The dye concentration in the aqueous solution was determined by using a UV-VIS spectrophotometer (Shimadzu-1601).

\section{Procedure}

\section{Batch adsorption studies}

The removal of $\mathrm{MB}, \mathrm{CR}$, and VL using pre-treated DP was studied in batch adsorption experiments. A fixed pre-treated DP dosage of $2 \mathrm{~g} / \mathrm{L}$ was directly added into $100 \mathrm{~mL}$ desired synthetic dyes with concentration ranging from 50 to $400 \mathrm{ppm}$ contained in $250 \mathrm{~mL}$ Erlenmeyer flasks. Subsequently, these flasks were put in an orbiter shaker at a rate of $2000 \mathrm{rpm}$ for $2 \mathrm{~h}$ until reaching the equilibrium state [19]. Following the adsorption, the mixtures were centrifuged at $4000 \mathrm{rpm}$ to separate residual dye solution and pre-treated DP adsorbed. The residual concentration of the dyes was determined using a UV-VIS spectrophotometer. The removal efficiency for synthetic dyes and the amount of dye adsorbed were calculated by Eq. (1) and (2).

Removal efficiency $(\%)=\left(1-\frac{C_{e}}{C_{o}}\right) \times 100$

$\mathrm{q}_{\mathrm{e}}=\frac{\mathrm{C}_{\mathrm{o}}-\mathrm{C}_{\mathrm{e}}}{\mathrm{m}_{\mathrm{a}}} \times \mathrm{V}$

where $\mathrm{C}_{\mathrm{o}}$ and $\mathrm{C}_{\mathrm{e}}$ represent the initial and equilibrium dye concentrations $(\mathrm{mg} / \mathrm{L})$, respectively. $\mathrm{q}_{\mathrm{e}}, \mathrm{V}$ and $\mathrm{m}_{\mathrm{a}}$ are correspondence with the dye uptake amount (mg dye/g sorbent), the solution volume and the dose of adsorbent (g), respectively.

\section{Fixed-bed column study}

A plastic column whose internal diameter and height are 2 and $15 \mathrm{~cm}$, respectively are used to conduct the adsorption experiments. To prevent the wash-out of pre-treated DP and ensure sufficient liquid distribution, a fixed amount of pre-treated DP (3.5 g) was packed between glass wool and glass beads in the column. The average packed density of the adsorbent in the column was $0.322 \mathrm{~g} / \mathrm{cm}^{3}$. The dye solution of $200-600 \mathrm{ppm}$ concentration $\left(\mathrm{C}_{\mathrm{o}}\right)$ flowed in down-flow mode through the bed. A UV-Vis spectrophotometer was used to analyze samples of the effluent, collected at regular interval time every $20 \mathrm{~min}$, and the residual dye concentration $\left(\mathrm{C}_{\mathrm{t}}\right)$. The studied bed heights were 2, 4, and $6 \mathrm{~cm}$ and flow rates vary from $5-20 \mathrm{~mL} / \mathrm{min}$.

\section{Modeling of experimental data obtained from the column study}

Data accrued from column experiments could be modeled to assess scale-up capability. The breakthrough curve is constructed by plotting effluent solute concentration against time, could describe the dynamic behavior of a packed column. Accordingly, the point where the allowable solute concentration in the effluent is reached is termed as breakthrough point. To describe and predict the dynamic behavior of a fixed bed column, various models are devised. One of which is the Thomas model. The long-established model, derived from Langmuir adsorption-desorption kinetics, has the assumption of no axial dispersion and follows secondorder reversible reaction kinetics [7-9]. The model could be described by linear Eq. (3).

$\ln \left(\frac{\mathrm{C}_{\mathrm{o}}}{\mathrm{C}_{\mathrm{e}}}-1\right)=\frac{\mathrm{k}_{\mathrm{th}} \mathrm{q}_{\mathrm{o}} \mathrm{m}}{\mathrm{Q}}-\left(\mathrm{k}_{\mathrm{th}} \cdot \mathrm{C}_{\mathrm{o}}\right) \mathrm{t}$

where $k_{t h}, q_{0}, t$ is the Thomas model constant $(\mathrm{mL} / \mathrm{min}$ $\mathrm{mg}$ ), the equilibrium adsorbate uptake $(\mathrm{mg} / \mathrm{g})$, and total flow time (min), respectively. Accordingly, $\mathrm{m}$ and $\mathrm{Q}$ are the adsorbent dosage $(\mathrm{g})$ and the flow rate $(\mathrm{mL} / \mathrm{min}) . \mathrm{k}_{\mathrm{th}}$ and $\mathrm{q}_{0}$ value were calculated from the linear representation of $\ln \left(\mathrm{C}_{\mathrm{o}} / \mathrm{C}_{\mathrm{t}}-1\right)$ against $t$. In this study, column breakthrough curves were described at various 
bed heights and flow rates using the Thomas model. As the solution flows across the column and the adsorption zone approaches the top of the column, the effluent concentration starts to rise rapidly. In this study, this breakthrough point was chosen at $C_{t} / C_{o}=0.05$, while the exhaution point was established when the effluent dye concentration approached the influent dye concentration $\left(\mathrm{C}_{\mathrm{t}} / \mathrm{C}_{\mathrm{o}}\right.$ approached 1.0).

\section{- RESULTS AND DISCUSSION}

\section{Characterization}

The surface morphology of raw and pre-treated Durian peels was characterized using SEM analysis as shown in Fig. 2(a). It can be seen that the raw durian peel exhibit rough surface covered with cellulosic fiber. The pre-treated Durian peels present highly rough, uneven surface with crater-like holes attributed to the typical structure of plant-derived cellulosic adsorbents. The FT-IR spectra of DP before and after pre-treatment was analyzed to determine functional groups on the surface of the samples (Fig. 2(b)). The broad band near $3500-3200 \mathrm{~cm}^{-1}$ indicate the $\mathrm{O}-\mathrm{H}$ stretching frequency of $\mathrm{OH}$ group in cellulose as well as intra and intermolecular hydrogen bonding of, possibly, polymeric compounds, alcohols, phenols, and carboxylic acids. The sharp absorbance at
2917 and $2854 \mathrm{~cm}^{-1}$ can be ascribed to the $\mathrm{C}-\mathrm{H}$ stretching frequency and relative peak centered at $1434 \mathrm{~cm}^{-1}$ coincides to $\mathrm{C}-\mathrm{H}$ bending. Accordingly, the sharp peak at $1742 \mathrm{~cm}^{-1}$ correspond with the stretching vibration of ester groups. Registered at $1634 \mathrm{~cm}^{-1}$, there occurred a relatively wide peak resulted from the stretching of the $\mathrm{C}=\mathrm{C}$ bonds in the aromatic compounds, and the absorbance at $1000 \mathrm{~cm}^{-1}$ is much likely due to the $\mathrm{C}-\mathrm{O}-\mathrm{R}$ or $\mathrm{C}-\mathrm{O}-\mathrm{H}$ group in esters and alcoholic groups. The absorption peaks around $1447 \mathrm{~cm}^{-1}$ correspond to the $\mathrm{C}-\mathrm{O}$ carboxyl bands [10,20-21]. After the treatment, the major change observed in the FTIR spectrum of pretreated DP is the disappearance of the peak at $1742 \mathrm{~cm}^{-1}$. This change reveals that the treatment of raw DP with $\mathrm{NaOH}$ successfully cleaved ester bonds to produce more hydroxyl groups on the surface [17]. Similar findings also showed the removal efficiency of adsorbents such as pine cone, White Pine (Pinus durangensis) sawdust, algae $D$. antarctica biomass for Methylene blue due to the interaction between dye molecules and active functional groups of adsorbents characterized by FTIR spectra analysis [22-24]. These results suggested that the existence of $\mathrm{O}-\mathrm{H}$ groups on pre-treated DP may favor for dye adsorption processes.
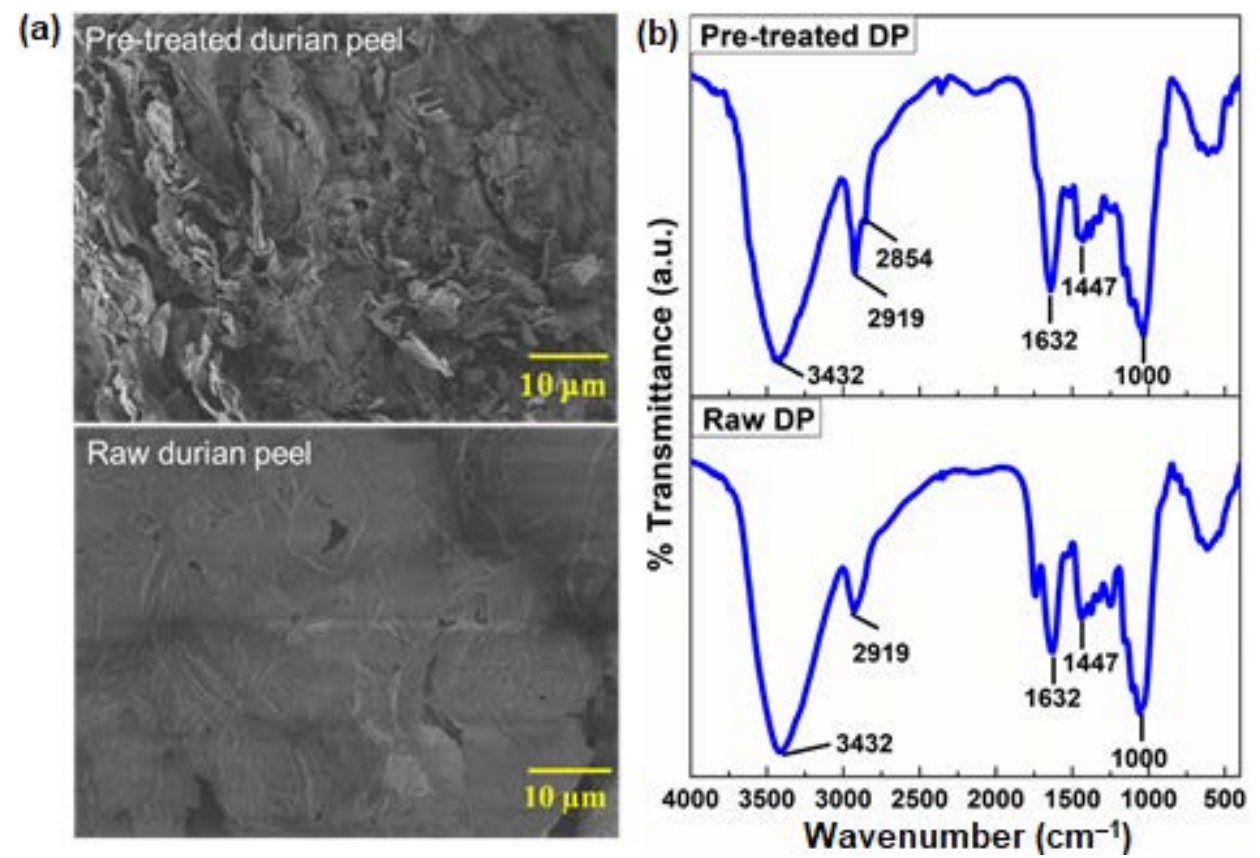

Fig 2. SEM image (a) and FTIR spectra (b) of durian peel with and without treatment 

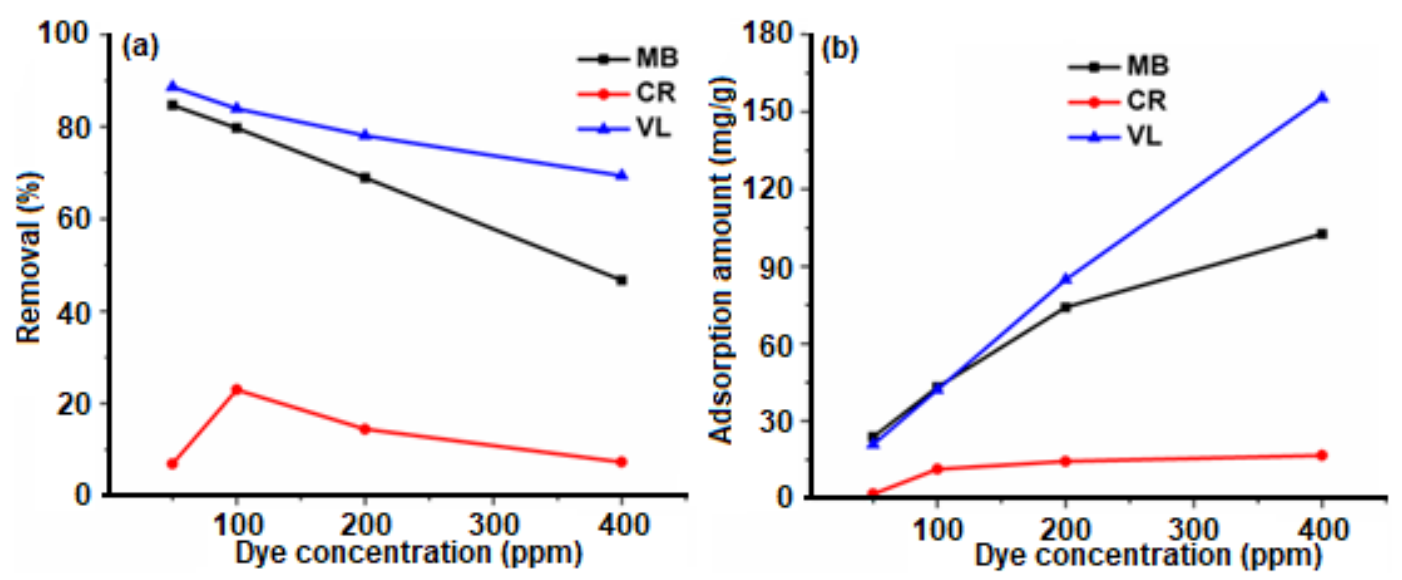

Fig.3. The effect of initial organic dyes concentration on removal efficiency (a) and (b) equilibrium adsorption amount
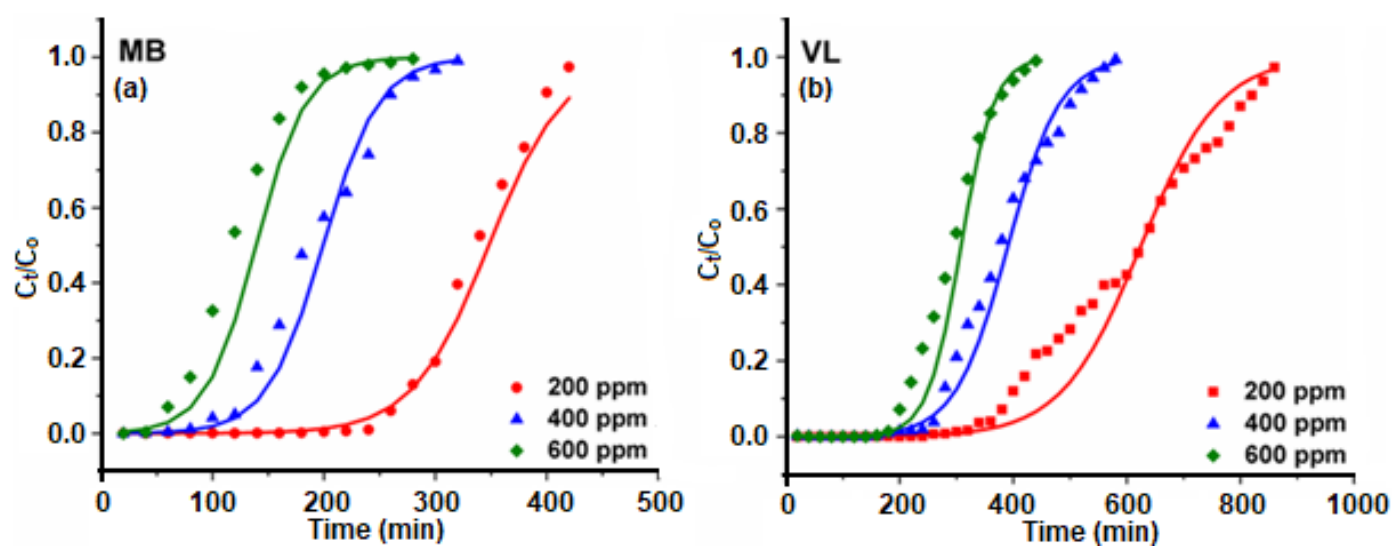

Fig 4. Breakthrough curves at different influent concentration for uptake of Methylene blue and Congo red

\section{Batch Adsorption Studies of Pre-Treated Durian Peel for Cationic and Anionic Dyes}

Fig. 3(a) shows the relationship between initial dye concentration (50-400 ppm) of three different dyes (MB, $\mathrm{CR}$, and $\mathrm{VL}$ ) and the removal efficiency using the pretreated durian adsorbents. To defeat the resistance refraining the dye transfer between the aqueous and the solid phase, the initial dye concentration is required. For $\mathrm{MB}$ and $\mathrm{VL}$ dyes, the percentage removal hit their peaks at $50 \mathrm{ppm}$ and rapidly dropped upon further increase in concentration to $400 \mathrm{ppm}$, while the removal efficiency of CR hit a peak of $100 \mathrm{ppm}$ and slightly decreased to $400 \mathrm{ppm}$. Comparatively, the pre-treated DP based adsorbents showed the higher adsorption efficiency for cationic dye than anionic dye. These results are explained by the negatively charged surface caused by $\mathrm{O}-\mathrm{H}$ groups on the surface of pre-treated DP. Resulting electrostatic forces of attraction will now help to enhance the uptake of the positively charged dye cations [25]. The increment in initial dyes concentration enhances the adsorption capacity of MB and VL dyes due to interaction between adsorbates and adsorbents [14]; the uptake amount was determined to be $23.84 ; 43.17 ; 74.12 ; 102.59 \mathrm{mg}$ dye/g adsorbent for $\mathrm{MB}$ and 20.93; 42.06; 84.90; $155.41 \mathrm{mg} / \mathrm{g}$ for VL at 50,100, 200, and $400 \mathrm{ppm}$, respectively. This suggested that the investigated adsorbent is favorable when it comes to the adsorption of cationic dye including $\mathrm{MB}$ and $\mathrm{VL}$, which was used for all further fixed-bed column adsorption studies.

\section{Effect of Various Parameters on Fixed-Bed Adsorption Column Studies}

\section{Effect of initial dye concentration}

Fig. 4 exhibit the breakthrough curves for $\mathrm{MB}$ and VL dye at a fixed flow rate of $10 \mathrm{~mL} / \mathrm{min}$, bed depth of $4 \mathrm{~cm}$ when varying influent concentration from 200 to $600 \mathrm{mg} / \mathrm{L}$. Visually, the adsorption capacity is proportional 
Table 1. Parameters of Thomas model derived under different influent concentration using linear regression analysis

\begin{tabular}{lccccc}
\hline Adsorbent & $\begin{array}{c}\text { Initial concentration } \\
(\mathrm{ppm})\end{array}$ & $\mathrm{R}^{2}$ & $\mathrm{~K}_{\text {th }}(\mathrm{mL} / \mathrm{min} \mathrm{mg})$ & $\mathrm{q}_{\mathrm{o}}(\mathrm{mg} / \mathrm{g})$ & $\begin{array}{c}\mathrm{Tb}(\mathrm{min}) \\
\left(\mathrm{C}_{\mathrm{t}} / \mathrm{C}_{\mathrm{o}}<0.05\right)\end{array}$ \\
\hline \multirow{3}{*}{ Methylene Blue (MB) } & 200 & 0.9322 & 0.1460 & 196.60 & 200 \\
& 400 & 0.9690 & 0.0995 & 225.11 & 120 \\
\hline \multirow{3}{*}{ Crystal Violet (VL) } & 600 & 0.9193 & 0.0738 & 235.80 & 360 \\
& 200 & 0.9528 & 0.0720 & 356.44 & 360 \\
& 400 & 0.9719 & 0.0540 & 445.10 & 260 \\
\hline
\end{tabular}
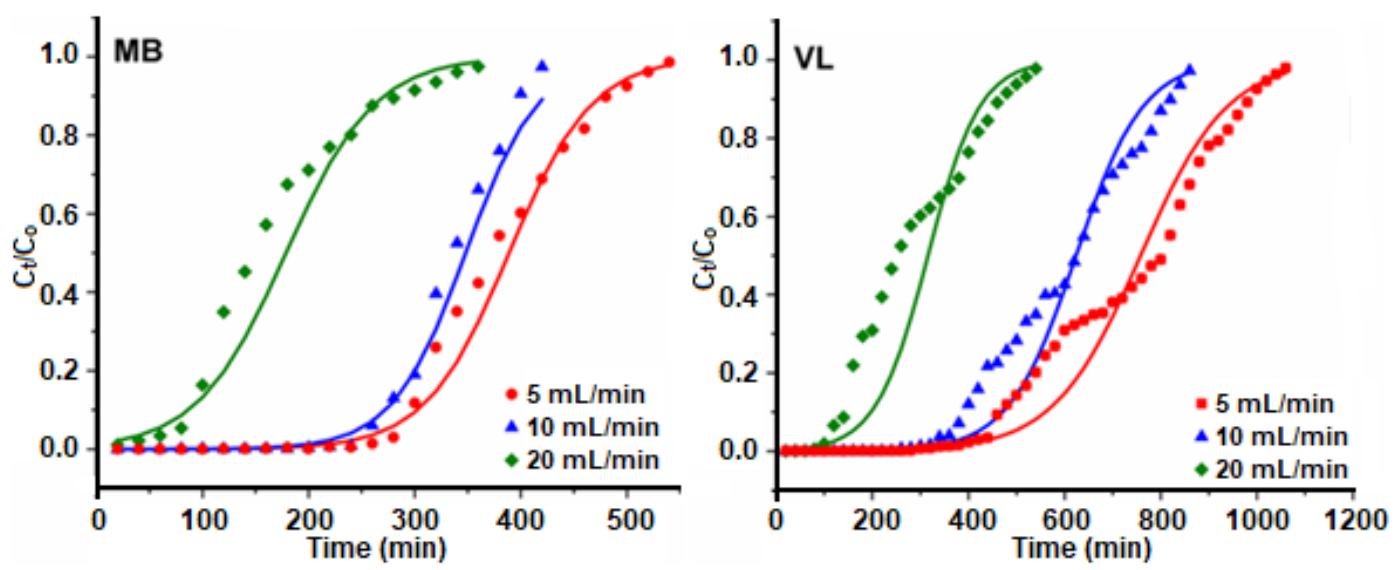

Fig 5. Breakthrough curves at different flow rates

to initial dye concentration. Both $\mathrm{MB}$ and VL dye witnessed a sharp reduction in the breakthrough time $\left(\mathrm{t}_{\mathrm{b}}\right)$ when dye concentration rises from 200 to $600 \mathrm{ppm}$. To be specific, breakthrough time declined from 200 to $60 \mathrm{~min}$ for MB and from 360 to $180 \mathrm{~min}$ for VL. This may be explained at lower influent concentration, the available active sites on pre-treated DP surface to be fully saturated caused a lower adsorbate amount and lower transport based on the decrease of the diffusion coefficient and mass transfer coefficient and thus longer time was required [2627]. With the increase in MB and VL concentration (200$600 \mathrm{ppm}$ ), the equilibrium adsorption amount was found to increase from 196.60 to $235.80 \mathrm{mg} / \mathrm{g}$ for $\mathrm{MB}$ and from 356.44 to $524.23 \mathrm{mg} / \mathrm{g}$ for VL (Table 1 ). This is given that the driving force for uptake process defeat the resistance refraining the dye transfer on the interface and the competition among the dye molecules in initial concentration increased resulting in enhanced adsorption capacity $[20,23]$.

However, Fig. 4 showed that the adsorption of DP for VL was well fit with Thomas model at higher initial influent concentration.

\section{Effect of flow rate}

The flow rate plays a crucial role in controlling the contact time between the solute and adsorbent surface. Fig. 5 illustrated the breakthrough curves for both dyes at a fixed initial concentration of $200 \mathrm{mg} / \mathrm{L}$, a bed height of $4 \mathrm{~cm}$ when varying flow rate from 5 to $20 \mathrm{~mL} / \mathrm{min}$. With increased flow rate, the time it takes for the adsorption zone to reach the top of the column got reduced, making the column of adsorbent reaches saturation level faster. At different flow rates, the fitting of the Thomas model gave different $\mathrm{R}^{2}$ values ranging from 0.9320 to 0.9762 for $\mathrm{MB}$ dye and from 0.8684 to 0.9648 for VL dye. Other essential parameters are provided in Table 2 . The breakthrough and exhaustion times came earlier with higher flow rates. For example, the breakthrough time for $\mathrm{MB}$ occurred around at 280, 240 and $80 \mathrm{~min}$ and for VL of 440,360, $120 \mathrm{~min}$ at the flow rate of 5, 10 and $20 \mathrm{~mL} / \mathrm{min}$. Similarly, the bed exhausted faster with a higher flow rate. This behavior could be justified by the lower residence of the solute in the fixed bed at higher flow rate time, which decrease contact time between adsorbates and adsorbents leading 
Table 2. Parameters of Thomas model derived under different flow rates using linear regression analysis

\begin{tabular}{|c|c|c|c|c|c|}
\hline Adsorbent & $\begin{array}{l}\text { Flow rate } \\
(\mathrm{mL} / \mathrm{min})\end{array}$ & $\mathrm{R}^{2}$ & $\mathrm{~K}_{\mathrm{th}}(\mathrm{mL} / \mathrm{min} . \mathrm{mg})$ & $\mathrm{q}_{\mathrm{o}}(\mathrm{mg} / \mathrm{g})$ & $\begin{array}{c}\mathrm{Tb}(\min ) \\
\left(\mathrm{C}_{\mathrm{t}} / \mathrm{C}_{\mathrm{o}}<0.05\right)\end{array}$ \\
\hline \multirow{3}{*}{ Methylene Blue (MB) } & 5 & 0.9762 & 0.1275 & 110.96 & 280 \\
\hline & 10 & 0.9320 & 0.1460 & 196.60 & 240 \\
\hline & 20 & 0.9450 & 0.1195 & 201.95 & 80 \\
\hline \multirow{3}{*}{ Crystal Violet (VL) } & 5 & 0.9648 & 0.0555 & 216.55 & 440 \\
\hline & 10 & 0.9528 & 0.0072 & 356.44 & 360 \\
\hline & 20 & 0.8684 & 0.0670 & 500.83 & $<120$ \\
\hline
\end{tabular}
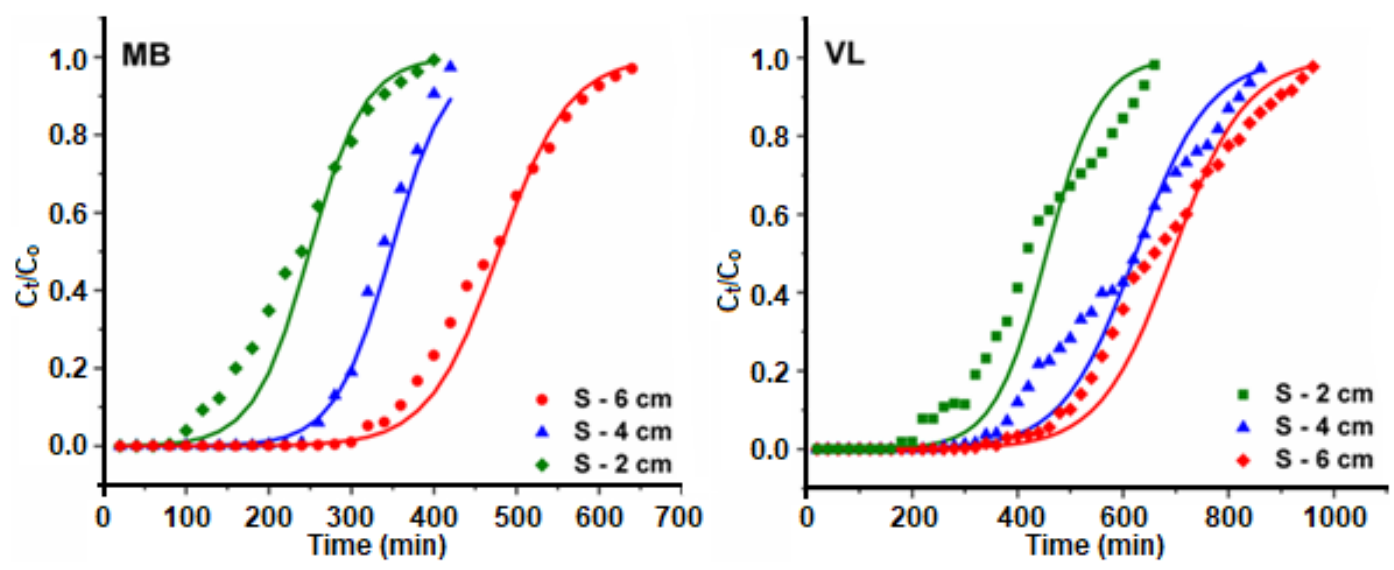

Fig 6. Breakthrough curves at different bed-depths

Table 3. Parameters of Thomas model derived under different bed-depths using linear regression analysis

\begin{tabular}{lccccr}
\hline Adsorbent & $\begin{array}{c}\text { Bed depth } \\
(\mathrm{cm})\end{array}$ & $\mathrm{R}^{2}$ & $\mathrm{~K}_{\mathrm{th}}(\mathrm{mL} / \mathrm{min} \mathrm{mg})$ & $\mathrm{q}_{\mathrm{o}}(\mathrm{mg} / \mathrm{g})$ & $\begin{array}{c}\mathrm{Tb}(\mathrm{min}) \\
\left(\mathrm{C}_{\mathrm{t}} / \mathrm{C}_{\mathrm{o}}<0.05\right)\end{array}$ \\
\hline \multirow{3}{*}{ Methylene Blue (MB) } & 2 & 0.9090 & 0.1485 & 166.15 & 100 \\
& 4 & 0.9320 & 0.1460 & 196.60 & $<260$ \\
\hline \multirow{3}{*}{ Crystal Violet (VL) } & 6 & 0.9820 & 0.1150 & 242.09 & 320 \\
& 4 & 0.9030 & 0.1000 & 303.32 & 220 \\
& 6 & 0.9530 & 0.0720 & 356.44 & 360 \\
\hline
\end{tabular}

to a lower degree of adsorption [27]. Accordingly, predicted maximum adsorption capacity from the Thomas model generally increased as the flow rate rises, implying that higher flow rate allowed more dye molecules bond with active function groups at available sites of CP efficiently [28]. The highest adsorption capacities were $201.95 \mathrm{mg} / \mathrm{g}$ and $500.83 \mathrm{mg} / \mathrm{g}$ for $\mathrm{MB}$ and $\mathrm{VL}$, respectively.

\section{Effect of bed height}

The effect of bed height was examined by allowing the dye solutions to pass through the column with different bed heights $(2,4$, and $6 \mathrm{~cm})$ at a fixed flow rate of $10 \mathrm{~L} / \mathrm{min}$ and initial influent concentration of 200 $\mathrm{mg} / \mathrm{L}$. From the plot, it is showed methylene blue and crystal violet could be removed completely at the bed depths of 2, 4, and $6 \mathrm{~cm}$. It was also observed that the occurrence of a breakthrough takes longer $\left(\mathrm{C}_{t} / \mathrm{C}_{\mathrm{o}}\right.$ approaches 0.05 ) with increasing bed height for all cases. The exhaustion time for VL is higher than that for MB. The exhaustion times were recorded at 100,260,320 min for MB while those for VL 220, 360, $460 \mathrm{~min}$ at the bed depth of 2,4 , and $6 \mathrm{~cm}$, respectively. The higher bed depths provides longer breakthrough times as the solute required sufficient residence time to diffuse deeply into 
the surface of the durian peels $[26,29]$. The plots of $C_{t} / C_{o}$ ratios versus time fitted with the breakthrough curves modeled by the Thomas model are shown in Fig. 5 . Table 3 listed the correlation coefficients and other statistics of the Thomas model. Thomas model yield high values $\mathrm{R}^{2}$ (0.9030-0.9820) indicating a reasonable fitness of the experimental data to the model. It also rules out the possibility for the external and internal diffusions of being the rate-limiting step. In addition, the exhaustion time also positively correlated with the bed-depth as resulted from increased adsorption capacity of a higher amount of adsorbent. The model-derived highest adsorption capacities of DP were 242.09 and $417.17 \mathrm{mg} / \mathrm{g}$ for MB and VL, respectively.

\section{- CONCLUSION}

The durian peel was found to be very efficient when it comes to adsorbing the cationic dyes, methylene blue, and crystal violet, on the column mode. The removal efficiency, breakthrough and exhaustion times depended strongly on the initial dye concentration, flow rate on effluent concentration, and bed height of fixed adsorption column. The breakthrough time and exhaustion time was proportional to bed depth and inversely proportional to initial concentration and flow rate. According to FTIR analysis, a number amount of critical functional groups like carbonyl and hydroxyl groups on the durian peel surface much likely contributed to its high efficiency for dye removals. The results of this study suggest the potential application of durian peels for sequestration of hazardous substances in the aqueous environment.

\section{- ACKNOWLEDGMENTS}

This research is funded by Nguyen Tat Thanh University Foundation for Science and Technology Development.

\section{- REFERENCES}

[1] Kurniawan, T.A., Chan, G.Y.S., Lo, W.-H., and Babel, S., 2006, Physico-chemical treatment techniques for wastewater laden with heavy metals, Chem. Eng. J., 118 (1-2), 83-98.

[2] Ahmad, A., Mohd-Setapar, S.H., Chuong, C.S., Khatoon, A., Wani, W.A., Kumar, R., and Rafatullah,
M., 2015, Recent advances in new generation dye removal technologies: novel search of approaches to reprocess waste water, $R S C A d v$., 5, 30801-30818.

[3] De Gisi, S., Lofrano, G., Grassi, M., and Notarnicola, M., 2016, Characteristics and adsorption capacities of low-cost sorbents for wastewater treatment: A review, Sustainable Mater. Technol., 9, 10-40.

[4] Bhatnagar, A., Sillanpää, M., and Witek-Krowiak, A., 2015, Agricultural waste peels as versatile biomass for water purification - A review, Chem. Eng. J., 270, 244-271.

[5] Ali, I., Asim, M., and Khan, T.A., 2012, Low cost adsorbents for the removal of organic pollutants from wastewater, J. Environ. Manage., 113, 170-183.

[6] Gautam, R.K., Mudhoo, A., Lofrano, G., and Chattopadhyaya, M.C., 2014, Biomass-derived biosorbents for metal ions sequestration: Adsorbent modification and activation methods and adsorbent regeneration, J. Environ. Chem. Eng., 2 (1), 239-259.

[7] Barakat, M.A., 2011, New trends in removing heavy metals from industrial wastewater, Arabian J. Chem., 4 (4), 361-377.

[8] Subhadrabandhu, S., and Ketsa, S., 2002, Durian, King of Tropical Fruit, Postharvest Biology and Technology Daphne Brasell Associates, Thordon, Wellington, New Zealand, 117-178.

[9] Tham, Y.J., Latif, P.A., Abdullah, A.M., ShamalaDevi, A., and Taufiq-Yap, Y.H., 2011, Performances of toluene removal by activated carbon derived from durian shell, Bioresour. Technol., 102 (2), 724-728.

[10] Chandra, T.C., Mirna, M.M., Sunarso, J., Sudaryanto, Y., and Ismadji, S., 2009, Activated carbon from durian shell: Preparation and characterization, J. Taiwan Inst. Chem. Eng., 40 (4), 457-462.

[11] Chandra, T.C., Mirna, M.M., Sudaryanto, Y., and Ismadji, S., 2007, Adsorption of basic dye onto activated carbon prepared from durian shell: Studies of adsorption equilibrium and kinetics, Chem. Eng. J., 127 (1-3), 121-129.

[12] Ahmad, M.A., Ahmad, N., and Bello, O.S., 2014, Modified durian seed as adsorbent for the removal 
of methyl red dye from aqueous solutions, Appl. Water Sci., 5 (4), 407-423.

[13] Kurniawan, A., Sisnandy, V.O.A., Trilestari, K., Sunarso, J., Indraswati, N., and Ismadji, S., 2011, Performance of durian shell waste as high capacity biosorbent for $\mathrm{Cr}(\mathrm{VI})$ removal from synthetic wastewater, Ecol. Eng., 37 (6), 940-947.

[14] Hameed, B.H., and Hakimi, H., 2008, Utilization of durian (Durio zibethinus Murray) peel as low cost sorbent for the removal of acid dye from aqueous solutions, Biochem. Eng. J., 39 (2), 338-343.

[15] Foo, K.Y., and Hameed, B.H., 2012, Textural porosity, surface chemistry and adsorptive properties of durian shell derived activated carbon prepared by microwave assisted $\mathrm{NaOH}$ activation, Chem. Eng. J., 187, 53-62.

[16] Nuithitikul, K., Srikhun, S., and Hirunpraditkoon, S., 2010, Kinetics and equilibrium adsorption of Basic Green 4 dye on activated carbon derived from durian peel: Effects of pyrolysis and post-treatment conditions, J. Taiwan Inst. Chem. Eng., 41 (5), 591598.

[17] Mallampati, R., Xuanjun, L., Adin, A., and Valiyaveettil, S., 2015, Fruit peels as efficient renewable adsorbents for removal of dissolved heavy metals and dyes from water, ACS Sustainable Chem. Eng., 3, 1117-1124.

[18] Martin, M.A., Siles, J.A., Chica, A.F., and Martin, A., 2010, Biomethanization of orange peel waste, Bioresour. Technol., 101 (23), 8993-8999.

[19] Nhung, N.T.H., Quynh, B.T.P., Thao, P.T.T., Bich, H.N., and Giang, B.L., 2018, Pretreated fruit peels as adsorbents for removal of dyes from water, IOP Conf. Ser. Earth Environ. Sci., 159, 1-8.

[20] Goswami, M., and Phukan, P., 2017, Enhanced adsorption of cationic dyes using sulfonic acid modified activated carbon, J. Environ. Chem. Eng., 5 (4), 3508-3517.

[21] Penjumras, P., Rahman, R.B.A., Talib, R.A., and Abdan, K., 2014, Extraction and characterization of cellulose from durian rind, Agric. Agric. Sci. Procedia, 2, 237-243.
[22] Salazar-Rabago, J.J., Leyva-Ramos, R., Rivera-Utrilla, J., Ocampo-Perez, R., and Cerino-Cordova, F.J., 2017, Biosorption mechanism of Methylene Blue from aqueous solution onto White Pine (Pinus durangensis) sawdust: Effect of operating conditions, Sustainable Environ. Res., 27 (1), 32-40.

[23] Yagub, M.T., Sen, T.K., Afroze, S., and Ang, H.M., 2014, Fixed-bed dynamic column adsorption study of methylene blue (MB) onto pine cone, Desalin. Water Treat., 55 (4), 1026-1039.

[24] Guarín, J.R., Moreno-Pirajan, J.C., and Giraldo, L., 2018, Kinetic study of the bioadsorption of methylene blue on the surface of the biomass obtained from the Algae D. antarctica, J. Chem., 2018, 2124845.

[25] Santhi, T., Manonmani, S., Vasantha, V.S., and Chang, Y.T., 2016, A new alternative adsorbent for the removal of cationic dyes from aqueous solution, Arabian J. Chem., 9 (Suppl. 1), 466-474.

[26] Mohammed, N., Grishkewich, N., Waeijen, H.A., Berry, R.M., and Tam, K.C., 2016, Continuous flow adsorption of methylene blue by cellulose nanocrystal-alginate hydrogel beads in fixed bed columns, Carbohydr. Polym., 136, 1194-1202.

[27] El Messaoudi, N., El Khomri, M., Dbik, A., Bentahar, S., Lacherai, A., and Bakiz, B., 2016, Biosorption of Congo red in a fixed-bed column from aqueous solution using jujube shell: Experimental and mathematical modeling, $J$. Environ. Chem. Eng., 4 (4), 3848-3855.

[28] Yu, J., Zhu, J., Feng, L., Cai, X., Zhang, Y., and Chi, R., 2015, Removal of cationic dyes by modified waste biosorbent under continuous model: Competitive adsorption and kinetics, Arabian J. Chem., In press.

[29] Sajab, M.S., Chia, C.H., Zakaria, S., and Sillanpää, M., 2015, Fixed-bed column studies for the removal of cationic and anionic dyes by chemically modified oil palm empty fruit bunch fibers: Single- and multi-solute systems, Desalin. Water Treat., 55 (5), 1372-1379. 